\title{
Cognitive Impairment and Associated Factors Among Chronic Kidney Disease Patients: A Comparative Cross-Sectional Study
}

\author{
Yibeltal Yismaw Gela' \\ Ayechew Adera Getu' \\ Aynishet Adane 2 \\ Bezawit Mulat Ayal' \\ Yonas Akalu (D) \\ Adugnaw Ambelu' \\ Mengistie Diress' \\ Yigizie Yeshaw $\mathbb{D}^{1,3}$
}

'Department of Physiology, College of Medicine and Health Sciences, University of Gondar, Gondar, Ethiopia;

${ }^{2}$ Department of Internal Medicine, College of Medicine and Health Sciences, University of Gondar, Gondar, Ethiopia ${ }^{3}$ Department of Epidemiology and Biostatistics, Institute of Public Health, College of Medicine and Health Sciences, University of Gondar, Gondar, Ethiopia

Correspondence: Yibeltal Yismaw Gela Email yibeltalyismaw7@gmail.com
Background: Cognitive impairment is one of the public health problems affecting 50 million people in the world. Chronic kidney disease (CKD) patients are at high risk to develop cognitive impairment which leads to poor quality of life, difficulty in adhering to medications, increased risk of mortality, and health resource utilization. However, there is no study done on the prevalence of cognitive impairment and associated factors among chronic kidney disease patients in Ethiopia.

Objective: This study aimed to assess the prevalence of cognitive impairment and associated factors among chronic kidney disease patients at the University of Gondar Comprehensive Specialized and Felege Hiwot Referral Hospitals in 2020, Northwest Ethiopia, 2020.

Methods: An institution-based comparative cross-sectional study was conducted at the University of Gondar Comprehensive Specialized and Felege Hiwot Referral Hospitals in 2020. A systematic random sampling technique was used to select the study participants. Data were collected using standard tools. Data were checked for its completeness and entered into Epi data version 3.0 then exported into STATA 14. Multi-variable logistic regression analysis was employed to identify associated factors of cognitive impairment among CKD patients, and variables having a p-value of $\leq 0.05$ were declared as significant.

Results: In this study, $116 \mathrm{CKD}$ patients and 116 age, sex, and educational level matched controls were included with a response rate of $100 \%$. The prevalence of cognitive impairment was $49.1 \%$ [95\% CI $(40 \%, 58.3 \%)]$ among CKD patients and 28.4\% [95\% CI $(20.9 \%, 37.5 \%)]$ among controls. Independent predictors of cognitive impairment among CKD patients were estimated glomerular filtration (eGFR) $<60 \mathrm{~mL} / \mathrm{min} / \mathrm{m}^{2}$ [AOR=3.9, 95\% CI (1.1-14.74)], proteinuria $[\mathrm{AOR}=6.0,95 \% \mathrm{CI}(1.83-20.3)]$, age greater than 65 years [AOR=4.0, 95\% CI (1.12-14.64)], and educational level of grade 8 and less $[\mathrm{AOR}=4.7,95 \% \mathrm{CI}(1.22-18.47)]$.

Conclusion: The prevalence of cognitive impairment among CKD patients was higher than healthy controls. Cognitive impairment was higher among CKD patients with eGFR $<60 \mathrm{~mL} /$ $\mathrm{min} / \mathrm{m}^{2}$, proteinuria, educational level of grade 8 and less, and age greater than 65 years. Therefore, there is a need to have a regular evaluation and follow-up of CKD patients for cognitive impairment.

Keywords: cognitive impairment, chronic kidney disease, SMMSE

\section{Background}

Chronic kidney disease (CKD) is characterized by progressive and irreversible damage to the kidney, which leads to the inability of the kidney to perform its function. ${ }^{1}$ Recently, the prevalence of CKD has been rapidly increasing as a result of higher prevalence of hypertension, diabetes mellitus, and obesity. ${ }^{2}$ A systematic 
review and meta-analysis done in the United Kingdom show that the prevalence of chronic kidney disease is $13.4 \%{ }^{3}$ In Africa, a systematic review study done shows that the prevalence of CKD is $13.9 \%{ }^{4}$ Institution-based studies in Ethiopia show that the prevalence of CKD ranges from $22.1 \%$ to $38.6 \% .^{5-7}$

Chronic kidney disease leads to hypertension, anemia, vascular dysfunction, uremia, proteinuria, systemic inflammation, and oxidative stress that are associated with cognitive impairment. ${ }^{8,9}$ Cognitive impairment is when a person has trouble remembering, learning new things, concentrating, or making decisions which is a common problem affecting CKD patients. ${ }^{10}$ The number of people living with severe cognitive impairment globally was 50 million in 2015. Of those 50 million, $60 \%$ of them living in low- and middle-income countries. ${ }^{11}$ This severe cognitive impairment prevalence is expected to increase to 82 million in 2030 and 152 million by $2050 .^{11}$

The prevalence of cognitive impairment in CKD patients ranges from $17 \%$ to $87 \%$ depending on severity. ${ }^{12-16}$ Its prevalence among CKD patients is $20 \%$ in the United Kingdom, ${ }^{17} 75.5 \%$ in China, ${ }^{18}$ and $53.8 \%$ in India. ${ }^{19}$ A comparative cross-sectional study in Nigeria showed that the prevalence of cognitive impairment CKD patients is $35.3 \%$ whereas for the control group it is $6 \%{ }^{20}$ Those chronic kidney disease patients with cognitive impairment have an increased risk of death, poor quality of life, difficulty in adhering to medications, and worse quality of emotional well-being. ${ }^{21-29}$ It is a major cause of morbidity and a determinant of the quality of life in the elderly chronic kidney disease patients. ${ }^{30,31}$ Among hemodialysis patients it is also associated with an approximately two-fold increased risk of both mortality and dialysis withdrawal. ${ }^{32}$

Moreover, cognitive impairment also leads to increase costs for governments, communities, families, and loss of productivity. $^{11,33}$ In Ethiopia, there was no study done previously on its prevalence and associated factors among CKD patients. Therefore, this study was conducted to determine the prevalence and predictors of cognitive impairment among chronic kidney disease patients.

\section{Materials and Methods}

\section{Study Setting and Period}

An institution-based comparative cross-sectional study was conducted at the University of Gondar
Comprehensive Specialized and Felege Hiwot Referral Hospitals from February 2020 to April 30, 2020.

\section{Study Population}

All adult CKD patients having follow-up at the University of Gondar Comprehensive Specialized and Felege Hiwot Referral Hospitals with all healthy adult patient's caregivers who came to the University of Gondar Comprehensive Specialized and Felege Hiwot Referral Hospitals matched for age, sex, and educational level were included in the study.

All CKD patients with visual, hearing, speaking difficulty, history of head trauma, AIDS, chronic liver disease, chronic obstructive pulmonary disease, and previous history of stroke were excluded from the study.

\section{Sample Size Calculation and Sampling Procedure}

Sample size was determined by using two population proportion formula by taking

$P_{1}=51.9 \%{ }^{34}$ and $P_{2}=33.3 \%{ }^{35}$ with $Z \alpha=95 \%, Z \beta=80 \%$.

$$
n_{1}=\frac{\left[Z_{\frac{\alpha}{2}} \sqrt{(r+1) \bar{p} \bar{q}}+Z_{1-\beta} \sqrt{r p_{1} q_{1}+p_{2} q_{2}}\right]^{2}}{r\left(p_{1}-p_{2}\right)^{2}}=110
$$

Where

$\mathrm{n}_{1}=$ sample size for CKD, $\mathrm{n}_{2}=$ sample size of control

$\mathrm{P}_{1}=$ proportion of cognitive impairment among CKD patients

$\mathrm{P}_{2}=$ proportion of cognitive impairment among healthy individuals

$Z_{\beta}=$ standard normal variate for power

$Z_{\alpha}=$ standard normal variate for the level of significance

$r=$ the ratio of $C K D$ group to the control group sample size

In this study $\mathrm{r}=1$ since equal sample size for both groups was taken.

$$
\begin{gathered}
\bar{p}=\frac{p_{1}+p_{2}}{2} \\
n_{2}=n_{1} \times r=110
\end{gathered}
$$

By using this formula for each group the sample size was 110 . By adding a non-response rate of 5\%, the total sample size for each group was 116. During the data collection period 360 and 400 patients were encountered at follow-up clinic of the University of Gondar Comprehensive Specialized and 
Felege Hiwot Referral Hospitals, respectively. Using the proportionate random sampling technique 55 and $61 \mathrm{CKD}$ patients were selected from the University of Gondar Comprehensive Specialized and Felege Hiwot Referral Hospitals, respectively, using systematic random sampling techniques with a $\mathrm{K}$ value of 7 . The first patient was the first one selected using the lottery method; then, every seventh patient was interviewed. For the control group participants matched with age, sex, and educational status were selected using consecutive sampling technique after selection of CKD patients (Figure 1).

\section{Operational Definitions}

Chronic kidney disease is defined as abnormalities of kidney structure or function, present for $>3$ months, with implications for health. ${ }^{1}$

The estimated glomerular filtration rate (eGFR) was calculated using the cockcroft-gault formula. ${ }^{36}$

Cognitive impairment: we have used the Standardized Mini Mental State Examination (SMMSE) tool.

Using this tool, those participants with educational level of $\leq$ grade 8 scores 22 and less and participants with educational level of $\geq$ grade 9 scores 24 and below from the total of 30 scores of SMMSE, had cognitive impairment. ${ }^{37}$

Social support was assessed by the Oslo Social Support Scale which scores out of 14 with 3-8 score poor social support, 9-11 score moderate social support, and 12-14 score strong social support. ${ }^{38}$

Anemia was defined as a hemoglobin concentration below $13 \mathrm{~g} / \mathrm{dl}$ in men and below $12 \mathrm{~g} / \mathrm{dl}$ in women. ${ }^{39}$
Khat chewer: individuals who had ever used khat at least once in their lifetime.

Cigarette smoker: individuals who had ever used cigarette at least once in their lifetime.

Alcohol drinker: the proportion of individuals who had ever used alcohol drinks such as tela, tej, katicala/areke, beer, wine, or other drinks that can cause intoxication at least once in their lifetime. ${ }^{40}$

Comorbidity: the presence of one or more of a documented case of the following diseases: hypertension, cardiovascular diseases, and diabetes mellitus.

Underweight: a person having a body mass index (BMI) of $<18.5 \mathrm{~kg} / \mathrm{m}^{2}$.

Normal weight: a person having BMI of $18.5 \mathrm{~kg} / \mathrm{m}^{2}-$ $24.9 \mathrm{~kg} / \mathrm{m}^{2}$.

Overweight: a person having BMI of $25 \mathrm{~kg} / \mathrm{m}^{2}$ $29.9 \mathrm{~kg} / \mathrm{m}^{2}$.

Obese: a person having BMI of $\geq 30 \mathrm{~kg} / \mathrm{m}^{2} \cdot{ }^{35,41}$

Hypertension: a person having systolic blood pressure of $140 \mathrm{mmHg}$ and/or diastolic blood pressure of $90 \mathrm{mmHg}$ and above ${ }^{42}$ or who is on antihypertensive treatment.

Proteinuria: the presence of protein in the urine, $\geq+1$ in the dipstick. ${ }^{43}$

\section{Data Collection Procedure and Tools}

Data were collected using interviewer-administered structured questionnaire which consists of sociodemographic characteristics, substance use history, Medical Record Review, physical measurements (weight, height, and blood pressure), and Standardized Mini-Mental State Examination tool (SMMSE tool) for cognition

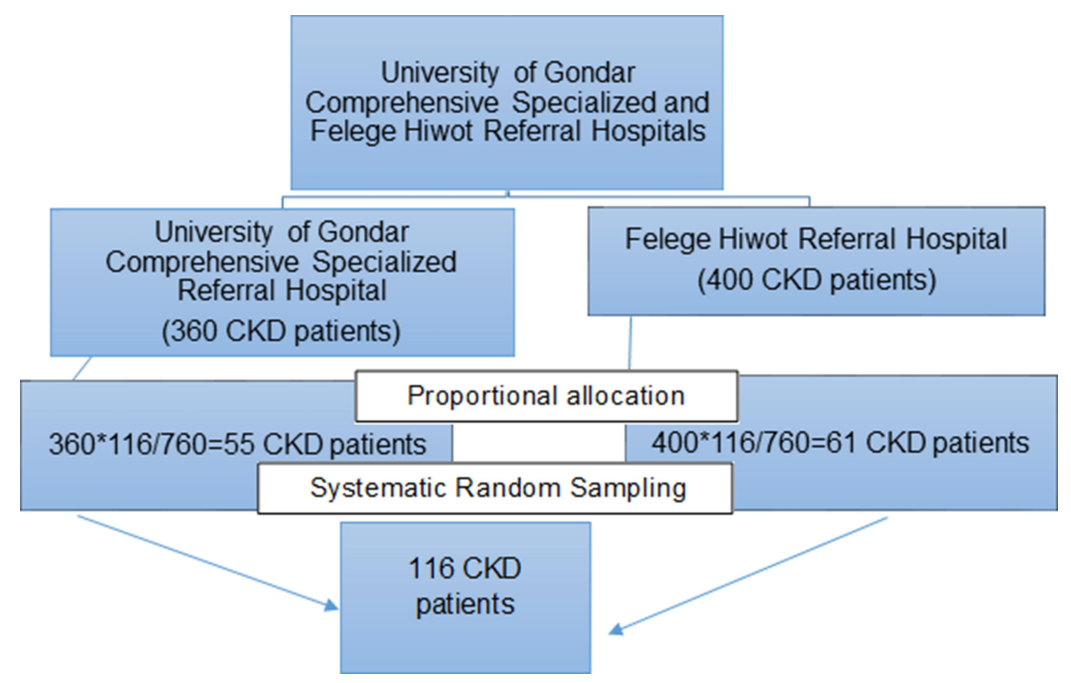

Figure I A flow chart shows the proportion of patients taking from the University of Gondar Comprehensive Specialized and Felege Hiwot Referral Hospitals, 2020. 
assessment. $^{37,44}$ A SMMSE tool was a cognitive impairment screening tool scored out of 30 which consists of questions that evaluate orientation (10 points), registration ( 3 points), attention, and calculation ( 5 points), recall ( 3 points), language and praxis ( 9 points). ${ }^{37}$ A digital blood pressure machine was used for measuring blood pressure and blood pressure was measured in a sitting position after a rest for 30 minutes. Again, weight and height were measured using height measuring stand with weighing machine.

\section{Data Analysis Procedure}

The collected data were checked for their completeness and coded then entered into Epi data version 3.0 then exported to STATA 14 for analysis. Descriptive statistics; frequency, percentage, and bar graph were used for categorical variables while median, interquartile range, mean, and standard deviation were used for continuous variables. Independent $t$-test was used to compare the mean difference for continuous variables of study groups whereas $\mathrm{X}^{2}$ test was used to show an association of the categorical variables among study groups. Both bi-variable and multivariable logistic regression analyses were done. Variables associated with cognitive impairment at p-value of $<0.25$ level in the bi-variable logistic regression were included in the multi-variable regression model. In the multi-variable logistic regression, variables having a $p$-value of $\leq 0.05$ with a 95\% confidence interval were declared as significantly associated with cognitive impairment. Finally, model fitness was checked by Hosmer and Lemeshow test. Using this test the final multiple logistic regression model p-value was 0.568 , since it was greater than 0.05 the model was fitted. Cronbach's alpha test for the SMMSE tool was done with a reliability coefficient value of 0.78 which shows good reliability of the tool.

\section{Data Quality Management}

To assure the data quality, high emphasis was given to designing the data collection tool. The questionnaire was translated to Amharic language by a language expert and retranslated back to English language by another expert for its consistency. Training regard to SMMSE tool, Medical Record Review, and way of measuring procedure to blood pressure height and weight was given for the data collectors by the principal investigator for one day. One week before data collection, the questionnaire was pretested on 12 study participants (6 for each group) at the Tibebe Ghion Specialized Hospital at Bahir Dar city.
Based on the pretest finding, necessary modification of questionnaire was taken. Throughout the data collection period, data collectors were supervised by the supervisor and principal investigator. For prevention of COVID-19 transmission, data collectors used protective materials such as face masks, sanitizers, and gloves with physical distance.

\section{Results}

\section{Sociodemographic Characteristic of Study Participants}

A total of 232 study participants with an equal proportion of CKD patients and healthy controls (116 each) were involved with a $100 \%$ response rate. The median age for both CKD patients and healthy control was 57.5 years with interquartile range of 29.5 and 30 years, respectively. The majority of the CKD patients attained primary school or less 72 (62\%) were male 75 (64.7\%), Orthodox Christianity follower 100 (86.2\%), married 69 (59.5\%), and employed 63 (54.3\%). Similarly, most of the control group participants attained primary school or less 70 (60.3\%) were male 75 (64\%), Orthodox Christianity follower 87 (75\%), married 96 (82.8\%), and employed 62 (53.5\%). The mean SMMSE score of the CKD patients was $22.3(\mathrm{SD} \pm 5.1)$ whereas for the control participants it was 24.1 ( $\mathrm{SD} \pm 4.6)$. The lifetime prevalence of khat chewing, alcohol use, and cigarette smoking among CKD patients were $1(0.9 \%), 9(7.8 \%)$, and $1(0.9 \%)$ respectively whereas for control it was 4 (3.5\%) for khat chewing, $31(26.7 \%)$ for alcohol intake and $2(1.72 \%)$ for cigarette smoking.

There were no significant differences between the study groups concerning a body mass index, substance use, religion, residence, social support score, income level and occupation. However, marital status, and mean SMMSE scores among study groups had a significant difference. Cognitive impairment also had a significant difference between the study groups $\left(X^{2}=10.4563, p=0.001\right)$ (Table 1).

\section{Clinical Characteristics of CKD Patients}

The mean creatinine and urea level among CKD patients were $2.2 \mathrm{mg} / \mathrm{dl}(\mathrm{SD} \pm 2.6)$ and $57.3 \mathrm{mg} / \mathrm{dl}(\mathrm{SD} \pm 14.2)$, respectively. Fifty-eight $(50 \%)$ patients had proteinuria and $72(62.1 \%)$ of them were anemic. Sixty-night (59.5\%) patients had an eGFR of less than $60 \mathrm{~mL} / \mathrm{min} / \mathrm{m}^{2}$ from those, $24(20.7 \%)$ patients had an eGFR of less than 
Table I Description and Comparisons of Sociodemographic and Clinical Characteristics of CKD Patients and Controls at University of Gondar Comprehensive Specialized and Felege Hiwot Referral Hospitals, 2020 ( $n=232$ )

\begin{tabular}{|c|c|c|c|c|c|}
\hline \multirow[t]{2}{*}{ Variables } & \multirow[t]{2}{*}{ Category } & \multicolumn{2}{|l|}{ Study Groups $(n=232)$} & \multirow{2}{*}{$\begin{array}{l}t / \mathbf{X}^{2} \\
\text { Value }\end{array}$} & \multirow[t]{2}{*}{ p-value } \\
\hline & & $\begin{array}{l}\text { CKD Group }(n=1 \mid 6) \text { Number } \\
(\%)\end{array}$ & $\begin{array}{l}\text { Control Group ( } n=1 \mid 6) \text { Number } \\
(\%)\end{array}$ & & \\
\hline Age (in Years) & Mean \pm SD & $54.1 \pm 17$ & $54.1 \pm 17.1$ & $0.011^{t}$ & 0.990 \\
\hline Sex & $\begin{array}{l}\text { Male } \\
\text { Female }\end{array}$ & $\begin{array}{l}75(64.7) \\
4 I(35.3)\end{array}$ & $\begin{array}{l}75(64.7) \\
4 I(35.3)\end{array}$ & 0.000 & 1.000 \\
\hline Religion & $\begin{array}{l}\text { Orthodox } \\
\text { Muslim } \\
\text { Protestant }\end{array}$ & $\begin{array}{l}100(86.2) \\
11(9.5) \\
5(4.3)\end{array}$ & $\begin{array}{l}87(75) \\
21(18.1) \\
8(6.9)\end{array}$ & 5.857 & 0.115 \\
\hline Educational level & $\begin{array}{l}\leq 8 \text { grade } \\
\text { Grade 9-12 } \\
\text { College and } \\
\text { above }\end{array}$ & $\begin{array}{l}72(62) \\
19(16.4) \\
25(21.6)\end{array}$ & $\begin{array}{l}70(60.3) \\
21(18.1) \\
25(21.6)\end{array}$ & 0.128 & 0.938 \\
\hline Marital status & $\begin{array}{l}\text { Single } \\
\text { Married } \\
\text { Divorced } \\
\text { Widowed }\end{array}$ & $\begin{array}{l}12(10.3) \\
69(59.5) \\
15(12.9) \\
20(17.2)\end{array}$ & $\begin{array}{l}7(6.0) \\
96(82.76) \\
6(5.2) \\
7(6)\end{array}$ & 15.850 & 0.001 \\
\hline Occupation & $\begin{array}{l}\text { Employed } \\
\text { Merchant } \\
\text { Farmer } \\
\text { Housewife }\end{array}$ & $\begin{array}{l}63(54.3) \\
21(18.1) \\
19(16.4) \\
13(11.2)\end{array}$ & $\begin{array}{l}62(53.5) \\
28(24.1) \\
11(9.5) \\
15(12.9)\end{array}$ & 3.284 & 0.350 \\
\hline $\begin{array}{l}\text { Monthly Income } \\
\text { (ETB) }\end{array}$ & $\begin{array}{l}\leq \mid 500 \\
|50|-250 \mid \\
2502-3502 \\
\geq 3503\end{array}$ & $\begin{array}{l}31(26.7) \\
8(6.9) \\
24(20.7) \\
53(45.7)\end{array}$ & $\begin{array}{l}20(17.4) \\
10(8.6) \\
20(17.2) \\
66(56.9)\end{array}$ & 4.378 & 0.223 \\
\hline Residence & $\begin{array}{l}\text { Urban } \\
\text { Rural }\end{array}$ & $\begin{array}{l}79(68.1) \\
37(31.9)\end{array}$ & $\begin{array}{l}87(75) \\
29(25)\end{array}$ & 10.355 & 0.244 \\
\hline Social support & $\begin{array}{l}\text { Poor social } \\
\text { support } \\
\text { Moderate } \\
\text { support } \\
\text { Strong support }\end{array}$ & $\begin{array}{l}24(20.7) \\
31(26.7) \\
6 I(52.6)\end{array}$ & $\begin{array}{l}28(24.1) \\
33(28.4) \\
55(47.4)\end{array}$ & 0.680 & 0.712 \\
\hline BMI $\left(\mathrm{Kg} / \mathrm{m}^{2}\right)$ & $\begin{array}{l}\text { Mean } \pm \text { SD } \\
18.5-24.9 \\
\geq 25\end{array}$ & $\begin{array}{l}22.30 \pm 2.90 \\
96(82.7) \\
61(58.1)\end{array}$ & $\begin{array}{l}22.09 \pm 2.66 \\
8(84.5) \\
18(I 5.5)\end{array}$ & $\begin{array}{c}-0.559^{t} \\
0.125\end{array}$ & $\begin{array}{l}0.576 \\
0.723\end{array}$ \\
\hline SMMSE Score & Mean \pm SD & $22.3 \pm 5.1$ & $24.1 \pm 4.6$ & $2.779^{t}$ & 0.005 \\
\hline Cognitive & Yes & $57(49.1)$ & $33(28.4)$ & 10.456 & 0.001 \\
\hline Impairment & No & $59(50.9)$ & $83(71.6)$ & & \\
\hline
\end{tabular}

Abbreviations: SD, standard deviation; ETB, Ethiopian birr; SMMSE, Standardized Mini Mental State Examination; ${ }^{\mathrm{t}} t$-test.

$30 \mathrm{~mL} / \mathrm{min} / \mathrm{m}^{2}$. Forty-seven (40.5\%) patients had eGFR $60 \mathrm{~mL} / \mathrm{min} / \mathrm{m}^{2}$ and above from those patients, $22(19 \%)$ hand eGFR $90 \mathrm{~mL} / \mathrm{min} / \mathrm{m}^{2}$ and above. At the time of data collection, the mean duration of disease was 2.7 years (SD \pm 2.1 ) and $81 \%$ of CKD patients have been living with CKD for 4 years and lower. Hundred-one (87.1\%) CKD patients had comorbidity. With regard to the treatment, all CKD patients had relied on supportive treatment. The blood 
Table 2 Factors Associated with Cognitive Impairment Among CKD Patients at the University of Gondar Comprehensive Specialized and Felege Hiwot Referral Hospitals, 2020

\begin{tabular}{|c|c|c|c|c|c|c|}
\hline \multirow[t]{2}{*}{ Variables } & \multirow[t]{2}{*}{ Category } & \multirow[t]{2}{*}{ Total N (\%) } & \multicolumn{2}{|c|}{ Cognitive Impairment } & \multicolumn{2}{|l|}{ OR (95\% Cl) } \\
\hline & & & $\begin{array}{l}\text { Yes }(n=57) \\
N(\%)\end{array}$ & $\begin{array}{l}\text { No }(n=59) \\
\text { N (\%) }\end{array}$ & COR & AOR \\
\hline \multirow[t]{2}{*}{ Age (year) } & $>65$ & $36(31.1)$ & $26(61.2)$ & $10(38.8)$ & 4.1 (1.74-9.68) & $4.0(1.12-14.64)^{*}$ \\
\hline & $\leq 65$ & $80(68.9)$ & $3 \mathrm{I}(27.8)$ & $49(72.2)$ & I & I \\
\hline \multirow[t]{3}{*}{ eGFR } & & & & & & \\
\hline & $\geq 60 \mathrm{~mL} / \mathrm{min} / \mathrm{m}^{2}$ & $47(40.5)$ & $9(19.2)$ & $38(80.8)$ & 1 & I \\
\hline & $<60 \mathrm{~mL} / \mathrm{min} / \mathrm{m}^{2}$ & $69(59.5)$ & $48(69.6)$ & $21(30.4)$ & $9.7(3.96-23.48)$ & $3.9(1.1-14.74)^{*}$ \\
\hline \multirow[t]{2}{*}{ Urea (mg/dl) } & & & & & & \\
\hline & Mean \pm SD & $57.3( \pm \mid 4.2)$ & $60.1 \pm 4.4$ & $54.7 \pm 2.8$ & $1.0(1.00-1.06)$ & $1.0(0.97-1.05)$ \\
\hline \multirow[t]{3}{*}{ Proteinuria } & & & & & & \\
\hline & No & $58(50)$ & $12(20.7)$ & $46(79.3) I$ & I & I \\
\hline & Yes & $58(50)$ & $45(77.6)$ & $(22.4)$ & |3.3(5.47-32.17) & $6.0(1.83-20.30)^{*}$ \\
\hline \multirow[t]{3}{*}{ Comorbidity } & & & & & & \\
\hline & No & $15(12.9)$ & $4(26.7)$ & II(73.3) & 1 & I \\
\hline & Yes & $101(87.1)$ & $53(52.5)$ & $48(47.5)$ & $3.0(0.91-10.17)$ & I.4(0.2I-7.50) \\
\hline \multirow[t]{3}{*}{ Anemia } & & & & & & \\
\hline & No & $44(37.9)$ & $10(22.7)$ & $34(77.3)$ & I & I \\
\hline & Yes & $72(62.1)$ & $47(65.3)$ & $25(34.7)$ & $6.4(2.72-15.04)$ & $2.6(0.82-8.10)$ \\
\hline \multirow[t]{3}{*}{ Sex } & & & & & & \\
\hline & Male & $75(64.7)$ & $40(48.1)$ & $35(5 \mid .9)$ & I & \\
\hline & Female & $4 I(35.3)$ & I7(58.8) & $24(4 \mid .2)$ & $0.62(0.28-1.33)$ & $0.8(0.24-2.49)$ \\
\hline \multirow[t]{4}{*}{ Educational level } & & & & & & \\
\hline & $\leq$ Grade 8 & $72(60)$ & $42(59.3)$ & $30(4 \mid .7)$ & I.8(0.7I-4.46) & $4.7(1.22-18.47)^{*}$ \\
\hline & Grade $9-12$ & $19(26.7)$ & $4(21.7)$ & I5(78.4) & $0.3(0.87-1.32)$ & $0.8(0.14-4.72)$ \\
\hline & College and above & $25(13.3)$ & II (44) & $14(56)$ & I & I \\
\hline \multirow[t]{4}{*}{ Social support } & & & & & & \\
\hline & Poor & $24(20.7)$ & |4(58.3) & $10(4 \mid .7)$ & $2.5(0.94-6.5 I)$ & $2.7(0.78-10.92)$ \\
\hline & Moderate & $3 I(26.7)$ & $21(67.7)$ & $10(32.3)$ & $3.7(1.49-9.31)$ & $2.2(0.56-7.26)$ \\
\hline & Strong & $61(52.6)$ & $22(36.1)$ & $39(63.9)$ & I & I \\
\hline
\end{tabular}

Note: *Statistically significant at $\mathrm{P} \leq 0.05$.

Abbreviations: AOR, adjusted odd ratio; $\mathrm{COR}$, crude odd ratio; $\mathrm{Cl}$, confidence interval; $\mathrm{N}$, number; SD, standard deviation.

pressure of 106 (91.4\%) CKD patients was within the normal range at the time of data collection (Table 2).

\section{Comparison of Cognitive Impairment Among CKD Patients and Controls}

The overall prevalence of cognitive impairment among CKD patients was $49.1 \%$ [ $95 \%$ CI $(40 \%, 58.3 \%)$ ] and among healthy controls it was $28.4 \% \quad[95 \%$ CI $(20.9 \%, 37.5 \%)]$

(Figure 2). The mean SMMSE score of CKD patients was significantly lower than healthy controls ( 22.3 versus $24.1, \mathrm{p}=0.001)$.

\section{Predictors of Cognitive Impairment} Among CKD Patients

Among variables entered into binary logistic regression age, educational level, social support, sex, eGFR, urea level, proteinuria, anemia, and comorbidity were associated with cognitive impairment at $p$-value of $<0.25$. However, in multi-variable logistic regression analysis four variables were significantly associated with cognitive impairment at $\mathrm{p}$-value of $\leq 0.05$. Those variables were, low eGFR, proteinuria, educational level, and age. Chronic kidney disease patients with eGFR $<60 \mathrm{~mL} /$ $\mathrm{min} / \mathrm{m}^{2}$ were 3.9 times [(AOR $=3.9,95 \%$ CI $(1.1-14.74)$ ] 


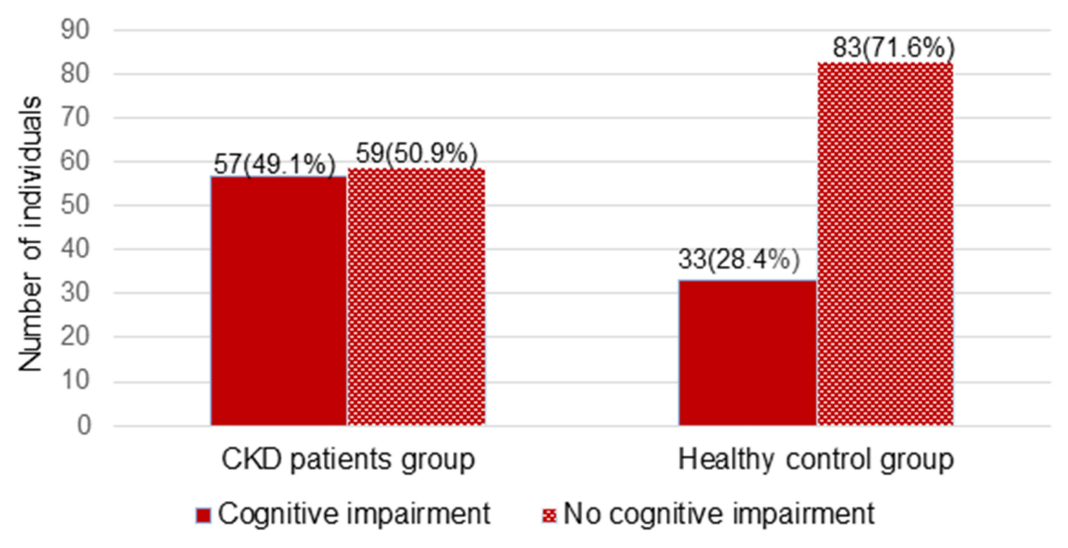

Figure 2 Prevalence of cognitive impairment among chronic kidney disease patients and healthy controls at the University of Gondar Comprehensive Specialized and Felege Hiwot Referral Hospitals, 2020.

more likely to develop cognitive impairment than those CKD patients having eGFR $\geq 60 \mathrm{~mL} / \mathrm{min} / \mathrm{m}^{2}$. Chronic kidney disease patients with proteinuria were 6 times [AOR=6.0, 95\% CI (1.83-20.30)] more likely to develop cognitive impairment than proteinuria negative CKD patients. Chronic kidney disease patients with age $>65$ years were 4.0 times $[\mathrm{AOR}=4.0,95 \% \mathrm{CI}(1.12-14.64)]$ more likely to develop cognitive impairments relative to CKD patients with age $\leq 65$ years. Those CKD patients attaining grade 8 and lower were 4.7 times $[\mathrm{AOR}=4.7$, 95\% CI (1.22-18.47)] more likely to develop cognitive impairment than those patients attaining college and above (Table 2).

\section{Discussion}

This research tried to offer insight on the magnitude of cognitive impairment and its significant predictors among CKD patients in comparison with healthy individuals.

In this study, the prevalence of cognitive impairment was $49.1 \%$ [ $95 \%$ CI $(40 \%-58.3 \%)$ ] among CKD patients. It was similar to the study conducted in Nigeria $(51.9 \%)$ and India (53.8\%). ${ }^{19,34}$ The possible reason for this cognitive impairment among CKD patients might be due to retention of different neurotoxins. Besides damaging neurons, different waste product accumulation in the blood may result in signaling disturbance in the brain regions, particularly in those involved in cognitive activities. ${ }^{45-47}$ However, a cross-sectional study conducted in the United Kingdom reported a lower prevalence $(20 \%)$ of cognitive impairment than the findings of this research. ${ }^{17}$ This difference might be because of a large proportion of participants with a higher educational level were included in the United Kingdom study, which might be lower the prevalence of cognitive impairment. ${ }^{19}$ Compare to study done in
China $(75.2 \%)$ this research finding was low due to the old age of study participants in China. ${ }^{18}$ Many studies showed that being an old age was a risk factor for cognitive impairment due to the neurotransmitter derangement during aging. ${ }^{25,48}$

The prevalence of cognitive impairment among healthy controls in this study was $28.4 \%$ [95\% CI (20.9-37.5\%)] which was similar to the study done in Central Africa republic (25\%), and Cameroon $(33.3 \%) .^{35,49}$ But findings from Nigeria $(6.3 \%)$, Botswana (9\%), and Congo $(18.8 \%)^{20,49}$ reported a lower prevalence of cognitive impairment. The possible reason for this difference might be due to variations in the tool used to assess cognitive impairment and sociodemographic differences of study participants. Community screening interview for dementia tool was used in Nigeria, Congo, and Botswana.

This study showed a higher prevalence of cognitive impairment among CKD patients than healthy controls. This finding was similar to the study done in Nigeria. ${ }^{50}$ It might be because of the effect of waste product retention in blood like urea and electrolyte due to a decrement of GFR or abnormality of glomerular capillary. Chronic kidney disease is also associated with many comorbidities that may lead to cognitive impairment like DM, hypertension, and anemia.

Decrease glomerular filtration rate was a significant predictor of cognitive impairment among CKD patients which was similar to other studies. ${ }^{20,51,52}$ Patients who had eGFR $<60 \mathrm{~mL} / \mathrm{min} / \mathrm{m}^{2}$ were 3.9 times more likely to develop cognitive impairment than those patients with eGFR $\geq 60 \mathrm{~mL} / \mathrm{min} / \mathrm{m}^{2}$. This could be due to the effect of neuronal toxic waste product accumulation in blood as glomerular filtration decreases. Specifically, increased 
levels of uremic toxins, neuropeptide $\mathrm{Y}$, increased parathyroid hormone, reduced levels of kidney neurotrophin, homocysteine, and vascular damage in the central nervous system may induce cognitive impairment. Noradrenergic, serotonergic, histaminergic neurons, and acetylcholinergic neurons in the encephalic trunk and hypothalamus are responsible for initiating the activity of the cortex and several subcortical regions. Those regions are responsible for sleep-wake cycles, memory, and attention. But those neurons might be sensitive to the concentration of uremic neurotoxins, result alterations in sleep patterns, mood, and attention in CKD which might lead to the development of cognitive impairment in CKD patients. ${ }^{9,45-47}$ Anemia which is common in CKD patients was associated with tissue hypoxia and decreased oxygen delivery to the brain which might lead to cognitive impairment. Erythropoietin is a neuroprotective agent so, its decrement in CKD patents might lead to the exposure of neurons to a neurotoxic substance. ${ }^{20,53}$ In addition to this electrolyte, and acid-base imbalance in CKD patients might be also the cause of cognitive impairment. ${ }^{45}$

Proteinuria was significantly associated with a decline in cognition. The odds of cognitive impairment was six times higher among CKD patients with proteinuria than patients with proteinuria negative. This result is in line with a systematic review and meta-analysis done in Greece. ${ }^{54}$ Proteinuria is a marker of generalized endothelial dysfunction and microvascular disease. It is associated with both brain atrophy and white matter demyelination with axonal $\operatorname{loss}^{55}$ which might be a possible reason for the risk of cognitive impairment in proteinuria.

Those patients who attained grade 8 and lower were more likely to develop cognitive impairment than those patients attaining college and above, which is in line with the study done in Jamaica. ${ }^{56}$ The reason might be due to formal education provides the necessary knowledge, understanding, skills, and competencies which constantly improve cognitive function. ${ }^{57}$ Education may create cognitive reserves by increasing synapse number or vascularization. $^{58}$

Increasing age was significantly associated with cognitive impairment. This finding is in agreement with other studies. ${ }^{20,35,49,51,52,56,58}$ This might be due to decline in gray matter volume, neurotransmitter, and neocortical synapses during aging which result in cognitive impairment. ${ }^{59-61}$

\section{Limitation of the Study}

The SMMSE tool is used only for screening purposes, so it is impossible to reach a diagnosis using this tool.

\section{Conclusion}

The findings of this study showed a higher prevalence of cognitive impairment among CKD patients than healthy controls. The independent predictors of cognitive impairment among CKD patients were eGFR $<60 \mathrm{~mL} / \mathrm{min} / \mathrm{m}^{2}$, proteinuria, educational level of grade 8 and less, and age greater than 65 years. Therefore, there is a need to have a regular evaluation and follow-up of CKD patients for cognitive impairment.

\section{Abbreviations}

BMI, Body Mass Index; CKD, Chronic Kidney Disease; CVD, Cardiovascular Disease; DM, Diabetes Mellitus; eGFR, Estimated Glomerular Filtration Rate; GFR, Glomerular Filtration Rate; SMMSE, Standardized Mini Mental State Examination.

\section{Data Sharing Statement}

The data will be available upon request from the corresponding author.

\section{Ethics Approval and Consent to Participate}

This study was conducted under the Declaration of Helsinki. Ethical clearance was obtained from the Institutional Review Board of the University of Gondar with approval number SOM/1849/06/2012. A permission letter was obtained from the University of Gondar Comprehensive Specialized and Felege Hiwot Referral Hospitals. Written Informed consent was obtained from the study participants to start data collection. The privacy and confidentiality of information were also kept properly.

\section{Consent for Publication}

Not applicable.

\section{Acknowledgments}

We would like to thank the University of Gondar for its sponsorship to conduct the study. In addition to this study participants also acknowledged for their willingness and cooperation. 


\section{Author Contributions}

All authors made substantial contributions during conception and design, acquisition of data, or analysis and interpretation of data; took part in drafting the article or revising it critically for important intellectual content; agreed to submit to the current journal; gave final approval of the version to be published; and agree to be accountable for all aspects of the work.

\section{Funding}

There is no funding to report.

\section{Disclosure}

None of the authors have any conflicts of interest for this work to declare.

\section{References}

1. Drueke TB, Wong G, Ronco P, et al. KDIGO 2018 Clinical practice guideline for the prevention, diagnosis, evaluation, and treatment of hepatitis c in chronic kidney. Kidney Int Suppl. 2018;8(3):91-165.

2. Chen T, Harris DC. Challenges of chronic kidney disease prevention. MJA. 2015;203(5):5-7. doi:10.5694/mja15.00241

3. Hill NR, Fatoba ST, Oke JL, et al. Global prevalence of chronic kidney disease - a systematic review and meta-analysis. PLoS One. 2016;11(7):1-18. doi:10.5061/dryad.3s7rd.Funding

4. Stanifer JW, Jing B, Tolan S, et al. The epidemiology of chronic kidney disease in sub-Saharan Africa: a systematic review and meta-analysis. Lancet Glob Heal. 2014;2(3):e174-e181. doi:10.1016/S2214-109X(14)70002-6

5. Kore C, Yohannes HM. Prevalence of chronic kidney disease and associated factors among patients with kidney problems public hospitals in Addis Ababa, Ethiopia. J Kidney. 2018;04(01):1-5 doi:10.4172/2472-1220.1000162

6. Bahrey D, Gebremedhn G, Mariye T, et al. Prevalence and associated factors of chronic kidney disease among adult hypertensive patients in Tigray teaching hospitals: a cross-sectional study. BMC Res Notes. 2019;12(1):562. doi:10.1186/s13104-019-4610-8

7. Damtie S, Biadgo B, Baynes HW, et al. Chronic kidney disease and associated risk factors assessment among diabetes mellitus patients at a tertiary hospital, Northwest Ethiopia. Ethiop J Health Sci. 2018;28 (6):691-700. doi:10.4314/ejhs.v28i6.3

8. Hannan M, Steffen A, Quinn L, Collins EG, Phillips SA, Bronas UG. The assessment of cognitive function in older adult patients with chronic kidney disease: an integrative review. J Nephrol. 2018. doi:10.1007/s40620-018-0494-2

9. Bronas UG, Puzantian H, Hannan M. Cognitive impairment in chronic kidney disease: vascular milieu and the potential therapeutic role of exercise. Biomed Res Int. 2017;2017:10. doi:10.1155/2017/ 2726369

10. Putkonen P, Kaaya EE, Bottiger D, et al. Cognitive impairment. Aids. 2011;6(3):257-263. doi:10.1097/00002030-199203000-00002

11. Guidelines World Health Organization. Risk Reduction of Cognitive Decline and Dementia; 2019.

12. Gronewold J, Hermann DM. Cognitive impairment in chronic kidney disease-prevalence, mechanisms and consequences. J Alzheimer's Dis Park. 2017;07(03):10-13. doi:10.4172/2161-0460.1000331
13. Hobson $\mathrm{P}$, Lewis A, Nair $\mathrm{H}$, et al. How common are neurocognitive disorders in patients with chronic kidney disease and diabetes? Results from a cross-sectional study in a community cohort of patients in North Wales, UK. BMJ Open. 2018;8(12):1-8. doi:10.1136/bmjopen-2018-023520

14. Lu R, Li Y, Shao X. The incidence prognosis and risk factors of cognitive impairment in maintenance haemodialysis patients. Karger AG. 2018;1-8. doi:10.1159/000493524

15. Elsayed E, Weiner DE. Cognitive impairment in hemodialysis patients. Am J Kidney Dis. 2007;49(2):183-185. doi:10.1053/j.ajkd.2006.11.035

16. Abdelrahman HMM, Elawam AEE, Alghitany AN. Cognitive impairment amongst older adults on haemodialysis. Middle East J Age Ageing. 2014;11(3):18-24. doi:10.5742/MEAA.2014.92483

17. Nulsen RS, Yaqoob MM, Mahon A, Stoby-fields M, Kelly M, Varagunam M. Prevalence of cognitive impairment in patients attending pre-dialysis clinic. $J$ Ren Care. 2008;44(20):121-126. doi:10.1111/j.1755-6686.2008.00028.x

18. Wang H, Fang C, Cai L, Dong B, Deng J. Chronic kidney disease and cognitive impairment among the very old in China. Aging Clin Exp Res. 2016;28(3):475-482. doi:10.1007/s40520-015-0433-1

19. Viji PC, Sreejith K, Sreelatha M. Chronic Kidney Disease and Cognitive Status. Int J Pharm Sci Res. 2017;8(5):2194-2199. doi:10.13040/IJPSR.0975-8232.8(5).2184-99

20. Egbi OG, Ogunrin O, Oviasu E. Prevalence and determinants of cognitive impairment in patients with chronic kidney disease: a cross-sectional study in Benin City, Nigeria. Ann Afr Med. 2015;14 (2):75-81. doi:10.4103/1596-3519.149877

21. Sorensen EP, Sarnak MJ, Tighiouart H, et al. The kidney disease quality of life cognitive function subscale and cognitive performance in maintenance hemodialysis patients. Am J Kidney Dis. 2012;60 (3):417-426. doi:10.1053/j.ajkd.2011.12.029

22. Drew DA, Weiner DE. Cognitive impairment in chronic kidney disease: keep vascular disease in mind. Kidney Int. 2014;85 (3):505-507. doi:10.1038/ki.2013.437

23. Gupta A, Mahnken JD, Johnson DK, et al. Prevalence and correlates of cognitive impairment in kidney transplant recipients. $B M C$ Nephrol. 2017;18(1):1-8. doi:10.1186/s12882-017-0570-1

24. Joseph SJ, Bhandari SS, Dutta S. Cognitive impairment and its correlates in chronic kidney disease patients undergoing haemodialysis. J Evol Med Dent Sci. 2019;8(36):2818-2822. doi:10.14260/jemds/2019/611

25. Gesualdo GD, Duarte JG, Zazzetta MS, et al. Cognitive impairment of patients with chronic renal disease on hemodialysis and its relationship with sociodemographic and clinical characteristics. Dement Neuropsychol. 2017;11(3):221-226. doi:10.1590/1980-57642016dn11-030003

26. Madan P, Kalra OP, Agarwal S, Tandon OP. Cognitive impairment in chronic kidney disease. Nephrol Dial Transplant. 2007;22 (2):440-444. doi:10.1093/ndt/gfl572

27. Raphael KL, Wei G, Greene T, Baird BC, Beddhu S. Cognitive function and the risk of death in chronic kidney disease. $\mathrm{Am}$ $J$ Nephrol. 2012;35(1):49-57. doi:10.1159/000334872

28. Lone EO, Connors M, Masson P, et al. Cognition in people with end-stage kidney disease treated with hemodialysis: a systematic review and meta-analysis. Am J Kidney Dis. 2016;67(6):925-935. doi:10.1053/j.ajkd.2015.12.028

29. Nasser MET, Shawki S, Yasser El Shahawy DS. Assessment of cognitive dysfunction in kidney disease. Saudi J Kidney Dis Transpl. 2012;23(6):1208-1214.

30. Madero M, Gul A, Sarnak MJ. Cognitive function in chronic kidney disease. Semin Dial. 2008;21(1):29-37. doi:10.1111/j.1525139X.2007.00384.x

31. Brodski J, Rossell SL, Castle DJ, Tan EJ. A systematic review of cognitive impairments associated with kidney failure in adults before natural age-related changes. J Int Neuropsychol Soc. 2019;25 (1):101-114. doi:10.1017/S1355617718000917 
32. Murray AM. Cognitive impairment in the aging dialysis and chronic kidney disease populations. Adv Chronic Kidney Dis. 2008;15 (2):123-132. doi:10.1053/j.ackd.2008.01.010

33. World Health Organization. Meeting on the Implementation of the Global Action Plan on the Public Health Response to Dementia 2017-2025. Geneva; 2018.

34. Williams UE, Owolabi MO, Ogunniyi A, Ezunu EO. Prevalence and pattern of neurocognitive impairment in Nigerians with chronic kidney disease. ISRN Neurol. 2013;2013:1-6. doi:10.1155/2013/374890

35. Tianyi FL, Agbor VN, Njamnshi AK, Atashili J. Factors associated with the prevalence of cognitive impairment in a rural elderly Cameroonian population: a community-based study in Sub-Saharan Africa. Dement Geriatr Cogn. 2019;47(1-2):104-113. doi:10.1159/ 000496825

36. Cockcroft DW, Gault MH. Prediction of creatinine clearance from serum creatinine. Nephron. 1976;16(1):31-41. doi:10.1159/ 000180580

37. Vertesi A, Lever JA, Molloy DW, et al. Standardized mini-mental state examination. Use and interpretation. Can Fam Physician. 2001;47(2):2018-2023.

38. Kocalevent RD, Berg L, Beutel ME, et al. Social support in the general population: standardization of the Oslo social support scale (OSSS-3). BMC Psychol. 2018;6(1):4-11. doi:10.1186/s40359-0180249-9

39. McLean E, Cogswell M, Egli I, Wojdyla D, De Benoist B. Worldwide prevalence of anaemia, WHO vitamin and mineral nutrition information system, 1993-2005. Public Health Nutr. 2009;12 (4):444-454. doi:10.1017/S1368980008002401

40. Yeshaw Y, Mossie A. Depression, anxiety, stress, and their associated factors among Jimma University staff, Jimma, Southwest Ethiopia, 2016: a cross-sectional study. Neuropsychiatr Dis Treat. 2017;13:2803-2812. doi:10.2147/NDT.S150444

41. Anderson AK. Prevalence of anemia, overweight/ obesity, and undiagnosed hypertension and diabetes among residents of selected communities in Ghana. Int $J$ Chronic Dis. 2017;2017:1-7. doi: $10.1155 / 2017 / 7836019$

42. Birhanu TE, Kassa MA, Getachew B, Dereje D, Gerbi A. Prevalence and predictors of cognitive impairment among hypertensive patients on follow up at Jimma University Medical Center, Jimma, Southwest Ethiopia. e-J Cardiovasc Med. 2019;7(3):117-125. doi:10.32596/ ejcm.galenos.2019.05.031

43. Adera H, Hailu W, Adane A. Prevalence of anemia and its associated factors among chronic kidney disease patients at University of Gondar Hospital, North West Ethiopia: a Hospital-based Cross Sectional Study. Int J Nephrol Renovasc Dis. 2019;12:219. doi:10.2147/IJNRD.S216010

44. Molloy DDW, Clarnette DR. Standardized mini mental state examination; 1999.

45. Viggiano D, Wagner CA, Martino G, et al. Mechanisms of cognitive dysfunction in CKD. Nat Rev Nephrol. 2020;30:1-18. doi:10.1038/ s41581-020-0266-9

46. Franco ÁD, Starosta RT, Roriz-Cruz M. The specific impact of uremic toxins upon cognitive domains. Braz J Nephrol. 2018;41 (1):1-9. doi:10.1590/2175-8239-JBN-2018-0033

Neuropsychiatric Disease and Treatment

\section{Publish your work in this journal}

Neuropsychiatric Disease and Treatment is an international, peerreviewed journal of clinical therapeutics and pharmacology focusing on concise rapid reporting of clinical or pre-clinical studies on a range of neuropsychiatric and neurological disorders. This journal is indexed on PubMed Central, the 'PsycINFO' database and CAS, and
47. Schneider SM, Kielstein JT, Braverman J, Novak M. Cognitive function in patients with chronic kidney disease: challenges in neuropsychological assessments. Semin Nephrol. 2015;35(4):304-310. doi:10.1016/j.semnephrol.2015.06.002

48. Hermann DM, Kribben A, Bruck H. Cognitive impairment in chronic kidney disease: clinical findings, risk factors and consequences for patient care. J Neural Transm. 2014;121(6):627-632. doi:10.1007/ s00702-014-1160-z

49. Angelique M, Powell J, Thorogood M. Prevalence of dementia and cognitive impairment among older people in sub-Saharan Africa: a systematic review. Bull World Heal Organ. 2013;91(8):773-783. doi:10.2471/BLT.13.118422

50. Williams UE, Owolabi MO, Ogunniyi A, Ezunu EO. Prevalence and pattern of neurocognitive impairment in Nigerians with stages 3 to 5 chronic kidney disease. ISRN Neurol. 2013;2013:1-6. doi:10.1155/ 2013/374890

51. Chen YC, Weng SC, Liu JS, Chuang HL, Hsu CC, Tarng DC. Severe decline of estimated glomerular filtration rate associates with progressive cognitive deterioration in the elderly: a Community-Based Cohort Study. Sci Rep. 2017;7:1-10. doi:10.1038/srep42690

52. Burns CM, Knopman DS, Tupper DE, et al. Prevalence and risk of severe cognitive impairment in advanced chronic kidney disease. J Gerontol. 2018;73(3):393-399. doi:10.1093/gerona/glx241/4737238

53. Chowdhury S, Chakraborty PP. Does anemia affects cognitive functions in neurologically intact adult patients: two year cross sectional study at rural tertiary care hospital. J Fam Med Prim Care. 2017;6 (2):169-170. doi:10.4103/jfmpc.jfmpc

54. Georgakis MK, Dimitriou NG, Karalexi MA, et al. Albuminuria in association with cognitive function and dementia: a systematic review and meta-analysis. $J$ Am Geriatr Soc. 2017;65 (6):1190-1198. doi:10.1111/jgs.14750

55. Knopman DS, Mosley TH, Bailey KR, Jack CR, Schwartz GL, Turner ST. Associations of microalbuminuria with brain atrophy and white matter hyperintensities in hypertensive sibships. J Neurol Sci. 2008;271(1-2):53-60. doi:10.1016/j.jns.2008.03.009

56. Waldron $\mathrm{N}$, Laws $\mathrm{H}$, James $\mathrm{K}$, et al. The prevalence of cognitive impairment among older adults in Jamaica. WIMJ Open. 2015;30:71-75. doi:10.7727/wimjopen.2014.003

57. Parisi JM, Rebok GW, Xue Q, et al. The Role of Education and Intellectual Activity on Cognition. J Aging Res. 2012;2012:20-24. doi:10.1155/2012/416132

58. Lee S, Buring JE, Cook NR, Grodstein F. The relation of education and income to cognitive function among professional women. Neuroepidemiology. 2006;26(2):93-101. doi:10.1159/000090254

59. Legdeur N, Heymans MW, Comijs HC, Huisman M, Maier AB, Visser PJ. Age dependency of risk factors for cognitive decline. BMC Geriatr. 2018;18(1):1-10. doi:10.1186/s12877-018-0876-2

60. Terry RD, Katzman R. Life span and synapses: will there be a primary senile dementia? Neurobiol Aging. 2001;22(3):347-348. doi:10.1016/S0197-4580(00)00250-5

61. Harada CN, Natelson Love MC, Triebel KL. Normal cognitive aging. Clin Geriatr Med. 2013;29(4):737-752. doi:10.1016/j.cger.201 3.07 .002 is the official journal of The International Neuropsychiatric Association (INA). The manuscript management system is completely online and includes a very quick and fair peer-review system, which is all easy to use. Visit http://www.dovepress.com/testimonials.php to read real quotes from published authors. 